\title{
Oceanographic and topographic conditions structure benthic meiofauna communities in Weddell Sea, Bransfield Strait and Drake Passage (Antarctic)
}

\author{
Veit-Köhler Gritta', Stephan Durst' ${ }^{1,2}$, Jan Schuckenbrock ${ }^{1,2}$, Freija Hauquier ${ }^{3}$, Laura Durán Suja ${ }^{3,4}$, Boris \\ Dorschel $^{5}$, Ann Vanreusel ${ }^{3}$ and Pedro Martínez Arbizu' \\ ' Senckenberg am Meer, DZMB - German Centre for Marine Biodiversity Research, Südstrand 44, \\ 26382 Wilhelmshaven, Germany \\ E-mail: gveit-koehler@senckenberg.de \\ 2 Carl von Ossietzky University Oldenburg, Department of Biology and Environmental Science, \\ Biodiversity and Evolution, 26111 Oldenburg, Germany \\ 3 Marine Biology Research Group, Ghent University, Krijgslaan 281/Sterre S8, 9000 Ghent, Belgium \\ ${ }^{4}$ School of Life Sciences, Heriot-Watt University, Edinburgh, EH1 4 4AS, United Kingdom \\ 5 Alfred-Wegener-Institut Helmholtz-Zentrum für Polar- und Meeresforschung, Van-Ronzelen-Str. 2, \\ 27568 Bremerhaven, Germany
}

The marine environment of the tip of the Antarctic Peninsula is characterised by three oceanographically distinct regions for which we linked continental-slope meiofaunal patterns and environmental drivers on a large scale. Samples for meiofauna communities and sediment analyses were collected with a multicorer, water-column data were derived from water samples and CTD recordings [1]. Meiofauna communities including individuals from 19 higher taxa were compared to a set of 16 environmental variables. We detected significant differences between the communities of Weddell Sea and those of Bransfield Strait and Drake Passage. The amount of phytopigments in the sediment, their freshness and the silt and clay content were driving factors for this separation. The highest meiofauna abundances were found at slopes in the Weddell Sea. Food banks may facilitate high standing stocks. There, the highest ever recorded copepod percentages for the Antarctic were related to the highest phytopigment contents while nematodes [2] were extremely abundant even in deeper sediment layers at stations with fresh organic material. For Bransfield Strait and Drake Passage a sampling scheme of slopes and adjacent troughs was applied. The two regions were divided into three geographical "areas" with the two "habitat" types investigated for each area. Multivariate non-parametric permutational analysis of variance (PERMANOVA) showed that Bransfield Strait and Drake Passage slope and trough meiofauna communities significantly differed between and within regions. The responsible environmental drivers were 7 out of 11 water-column and sediment-bound factors. Environmental characteristics of the benthic habitat are dependent on large-scale oceanographic conditions and are thus sensitive to changes in water temperature, salinity, sea-ice cover and the related primary production.

\section{References}

- Hauquier F., Veit-Köhler G. 2013. 3.10 Meiofauna and water masses: looking for the link. In: Gutt J. (ed.) The Expedition of the Research Vessel "Polarstern" to the Antarctic in 2013 (ANT-XXIX/3). Berichte zur Polar- und Meeresforschung 665:73-77.

- auquier F., Durán Suja L., Gutt J., Veit-Köhler G., Vanreusel A. 2015. Different oceanographic regimes in the vicinity of the Antarctic Peninsula reflected in benthic nematode communities. PLoS ONE 10(9):e0137527. doi:10.1371/journal.pone.0137527. 